\title{
Uncertainty Analysis of the Potential Hazard of MCCI during Severe Accidents for the CANDU6 Plant
}

\author{
Sooyong Park, Kwang-Il Ahn, and YongMann Song \\ Korea Atomic Energy Research Institute, Daejeon 305-353, Republic of Korea \\ Correspondence should be addressed to Sooyong Park; sypark@kaeri.re.kr \\ Received 18 September 2014; Accepted 8 February 2015 \\ Academic Editor: Arkady Serikov
}

Copyright ( 2015 Sooyong Park et al. This is an open access article distributed under the Creative Commons Attribution License, which permits unrestricted use, distribution, and reproduction in any medium, provided the original work is properly cited.

\begin{abstract}
This paper illustrates the application of a severe accident analysis computer program to the uncertainty analysis of molten coriumconcrete interaction (MCCI) phenomena in cases of severe accidents in CANDU6 type plant. The potential hazard of MCCI is a failure of the reactor building owing to the possibility of a calandria vault floor melt-through even though the containment filtered vent system is operated. Meanwhile, the MCCI still has large uncertainties in several phenomena such as a melt spreading area and the extent of water ingression into a continuous debris layer. The purpose of this study is to evaluate the MCCI in the calandria vault floor via an uncertainty analysis using the ISAAC program for the CANDU6.
\end{abstract}

\section{Introduction}

The phenomenon known as molten corium-concrete interaction (MCCI) has been recognized as an important aspect of severe reactor accidents. During transients followed by the failure of certain emergency core cooling systems, the core may eventually melt due to the generation of decay heat, leading to a severe accident. If the safety features of the CANDU6 plant fail to arrest the accident within the calandria vessel, the corium (molten core debris) will fall into the calandria vault and attack the concrete walls and floor.

The potential hazard of MCCI is a failure of the reactor building $(\mathrm{R} / \mathrm{B})$ owing to the possibility of a calandria vault floor melt-through even though the containment filtered vent system (CFVS) is operated. The calandria vault floor meltthrough refers to the process of concrete decomposition and destruction associated with a corium melt interacting with the concrete floor in the calandria vault. The concrete properties, corium amount, corium distribution in the calandria vault, debris bed configuration and calandria vault conditions (cooling water availability), debris power, and heat transfer are important parameters affecting the calandria vault floor melt-through.

MCCI phenomenon has large uncertainties in several phenomena such as a melt spreading area, the particle size if the debris is particulated, the particle size distribution or debris bed permeability if significant particulation has occurred, and the extent of water ingression into a continuous debris layer. The purpose of this study is to evaluate the MCCI in the calandria vault floor through an uncertainty analysis using the ISAAC (Integrated Severe Accident Analysis Code for CANDU Plant) computer program [1] for a CANDU6.

\section{Methodology}

This application was performed using an ISAAC model of Wolsong-1 plant [2], which is a typical CANDU6, for an estimate of the MCCI phenomena. A station blackout (SBO) scenario, where all off-site power is lost and the diesel generators (DGs) fail is simulated as an initiating event of a severe accident sequence. The scenario has been taken as a very low-frequency, but high-risk, accident event. During an SBO event, the initiating event is a loss of class IV and class III power, causing a loss of pumps used in systems such as the primary heat transport system, moderator cooling, shield cooling, steam generator feed water, and recirculating cooling water. The class IV power supplies AC loads that can be interrupted indefinitely without affecting the personnel or plant safety and the class III power supplies AC loads that can tolerate the short interruption (one to three minutes) 
required to start the standby generators without affecting the personnel or plant safety but are required for safe plant shutdown.

The thermal hydraulic and severe accident phenomenological analyses for the evaluation were performed using the ISAAC 4.03 program. The ISAAC code is a system level computer code capable of performing integral analyses of potential severe accident progressions in nuclear power plants, whose main purpose is to support a level 2 probabilistic safety assessment or severe accident management strategy developments. The ISAAC program has been developed based on MAAP4 [3]. Therefore, most of the basic thermal hydraulic and radiological models of those two computer codes are similar. Only the plant specific system models are different from each other [4]. The code employs lots of user options for supporting sensitivity and uncertainty analysis. The present application was mainly focused on determining an estimate of the axial/radial concrete erosion and corium coolability in the reactor cavity during MCCI. The key modeling parameters and phenomenological models employed for the present uncertainty analysis were related to heat transfer coefficients, concrete property, and corium debris configuration.

The ISAAC contains molten corium-concrete interaction models that evaluate a potential of concrete erosion and its phenomenological consequences for those accident sequences in which corium can accumulate in direct contact with concrete in the calandria vault. Heat transfer from corium can cause chemical decomposition of the concrete which releases water vapor and carbon dioxide off-gas and melting which causes concrete slag to enter the corium. Essential aspects of the description of coriumconcrete interactions are heat transferred from the debris to concrete, heat transferred within the concrete and its ablation, debris crusting, and solidification, chemical reactions within the debris, and effects of concrete slag addition into core debris, and heat transferred to the overlying coolant water.

The basic approach of this methodology was to (1) identify the ISAAC input parameters, sensitivity coefficients, and modeling options that describe or influence the MCCI phenomena, (2) prescribe likelihood descriptions of the potential range of these parameters, and (3) evaluate the code predictions using a number of random combinations of parameter inputs sampled from the likelihood distributions. This method of characterizing uncertainty in reactor accident progression is similar to the method used by Gauntt [5] where the MELCOR [6] code was used. In order to limit the number of "realizations" (code calculations) needed to characterize the full range of uncertainty, the Latin hypercube sampling method (LHS) was used to sample the input parameter distributions.

In order to quantify uncertainties addressed in the ISAAC code, a computer program, MOSAIQUE [7], was applied, which was recently developed by KAERI (Korea Atomic Energy Research Institute). The program consists of fully automated software to quantify uncertainties addressed in the thermal hydraulic analysis models or codes.
TABLE 1: Timings of key events for the station blackout scenario base case in the Wolsong-1 plant (based on ISAAC calculation).

\begin{tabular}{lc}
\hline Event & $\begin{array}{c}\text { Time (base case) } \\
\text { hours, (seconds) }\end{array}$ \\
\hline SG inventory depletion & $2.8(10,032)$ \\
Pressure tube rupture & $4.0(14,272)$ \\
CFVS first open & $6.7(24,034)$ \\
Calandria vessel inventory depletion & $11.5(41,558)$ \\
Calandria vessel failure & $45.6(164,188)$ \\
Calandria vault inventory depletion & $49.3(177,502)$ \\
Calandria vault floor rupture & $101.0(363,473)$ \\
Reactor building failure & $102.4(368,484)$ \\
\hline
\end{tabular}

\section{Analysis Results}

3.1. Base Case Analysis. In advance of uncertainty analyses, a simple base case analysis was performed. The selected scenario was a typical station blackout sequence without any recovery action. The base case does not credit any of the active heat sinks (all of the emergency core cooling systems and the feedwater systems) but relies only on passive heat sinks, particularly the initial water inventories of the primary heat transport system (PHTS), moderator, steam generator (SG) secondary side, end shields, and calandria vault. There was an assumption that the passive containment filtered vent system (CFVS) was operated. The CFVS is assumed to be operated with an opening pressure of $225 \mathrm{kPa}(\mathrm{a})$ and a closing pressure of $151 \mathrm{kPa}(\mathrm{a})$, where the orifice diameter was $0.2548 \mathrm{~m}$. Following the SBO accident, the sequence progresses to a severe core damage accident. Heat transfer from the PHTS to SGs causes the water in the SG secondary side to boil off. As a result, the pressure in the secondary side of the SGs increases gradually and causes the main steam safety valve (MSSV) to open and discharge steam from the secondary side to the environment outside the $\mathrm{R} / \mathrm{B}$. As the boil-off proceeds, the water in the SGs is depleted at about 2.8 hours (10,032 seconds) (Table 1 ) and the SGs are no longer a heat sink to remove heat from the PHTS. Thus, the pressure in the PHTS starts to increase until it reaches the PHTS liquid relief valve (LRV) set point of $10.16 \mathrm{MPa}$. The PHTS inventory is gradually lost through the LRVs resulting in a fuel channel dryout.

In parallel, the moderator heats up and the water level in the calandria vessel decreases gradually since the moderator cooling is assumed to be unavailable. With the loss of moderator as a heat sink, a fuel channel with the highest decay power ruptures at 4 hours (14,272 seconds). The channel locates between $5.016 \mathrm{~m}$ and $6.542 \mathrm{~m}$ above the calandria bottom. The channel is dried out at about 3.3 hours $(12,000$ seconds) and the calandria water level decreases to $6.0 \mathrm{~m}$ at 4.3 hours (15,335 seconds). Following the fuel channel rupture and core material relocation, the remaining water in the calandria vessel eventually boils off. The moderator inside the calandria vessel is depleted at about 11.5 hours (41,558 seconds) (Table 1 ) which is shown in Figure 1. The water in the calandria vault acts as a heat sink to cool the 


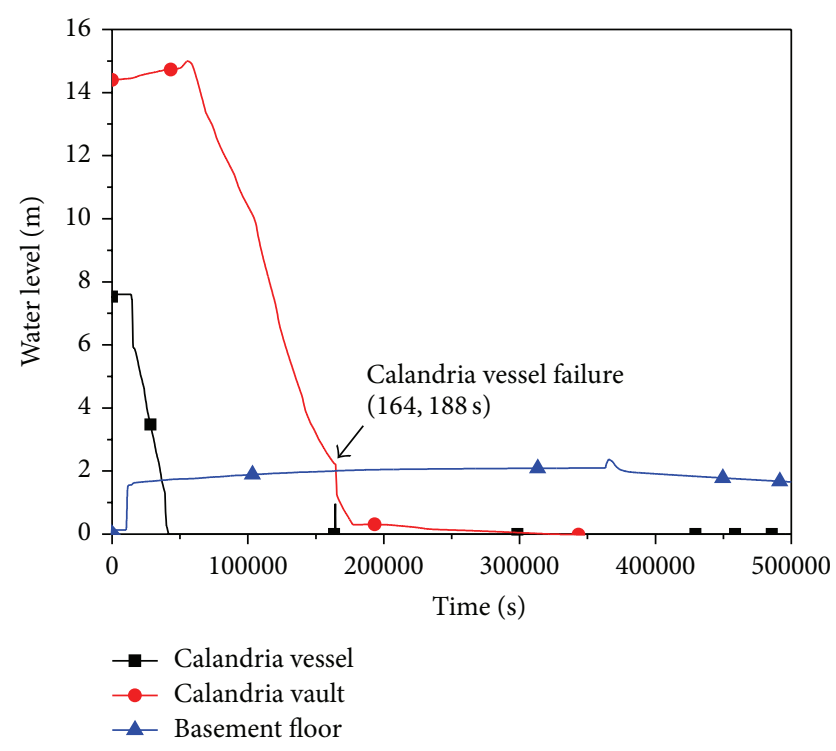

FIgURE 1: Water level behaviors in the calandria vessel, calandria vault, and R/B basement floor.

external calandria vessel wall and the vessel wall is intact as long as the wall is covered with cooling water. There is an assumption that the relocated molten corium on the calandria bottom would be coolable in the CANDU6 plant because the so-called in-vessel corium retention by external vessel cooling might be very feasible [8]. Steam generated in the calandria vault is released into the $\mathrm{R} / \mathrm{B}$. When the water level in the calandria vault reaches the calandria vessel bottom, the vessel bottom heats up rapidly from the heat generated by the core debris inside, and the vessel fails owing to creep (Figure 1). When the calandria vessel fails at 45.6 hours $(164,188$ seconds), the debris relocates into the calandria vault (Figure 2), where it is cooled by water. The calculation results are summarized in Table 1 and the time dependent behaviors of important variables for the Wolsong-1 plant are illustrated in Figure 1 through Figure 4. The value of ISAAC uncertain input parameters, which will be discussed below, for this base case was taken from the recommended value (the most likely value) of Table 2.

In the base case, the analysis focused on the water level behaviour in various locations, the corium mass behavior in various locations, the axial/radial concrete erosion in calandria vault, and the pressure behavior in R/B. After the water depletion in the calandria vault at about 49.3 hours (177,502 seconds) (Figure 1), the corium again started to heat up and resulted in continuously increasing concrete ablation (Figure 3). The calandria vault floor ruptured with the depth of $2.3 \mathrm{~m}$ at about 101.0 hours (363,473 seconds). There was an assumption that the calandria vault floor would be ruptured with the erosion depth of $2.3 \mathrm{~m}$ due to the mechanical instability even though the original floor depth was $2.44 \mathrm{~m}$. When the calandria vault floor ruptured, the corium discharged into the R/B basement floor (Figure 2) and a large amount of steam generated owing to the heat transfer between the hot corium and the accumulated water

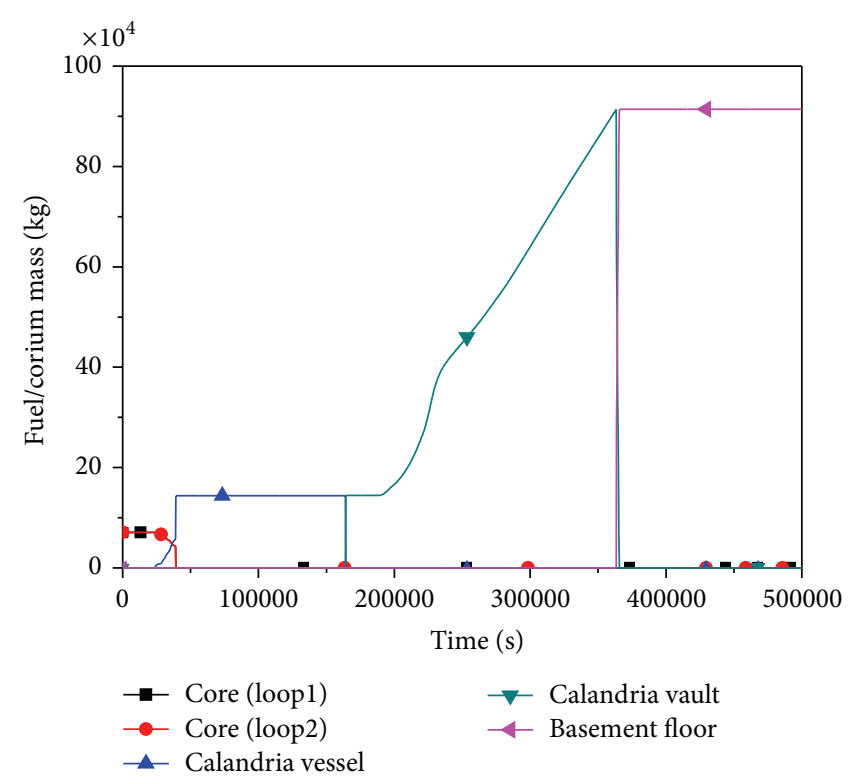

FIGURE 2: Fuel/corium mass behaviors in the core, calandria vessel, calandria vault, and $\mathrm{R} / \mathrm{B}$ basement floor.

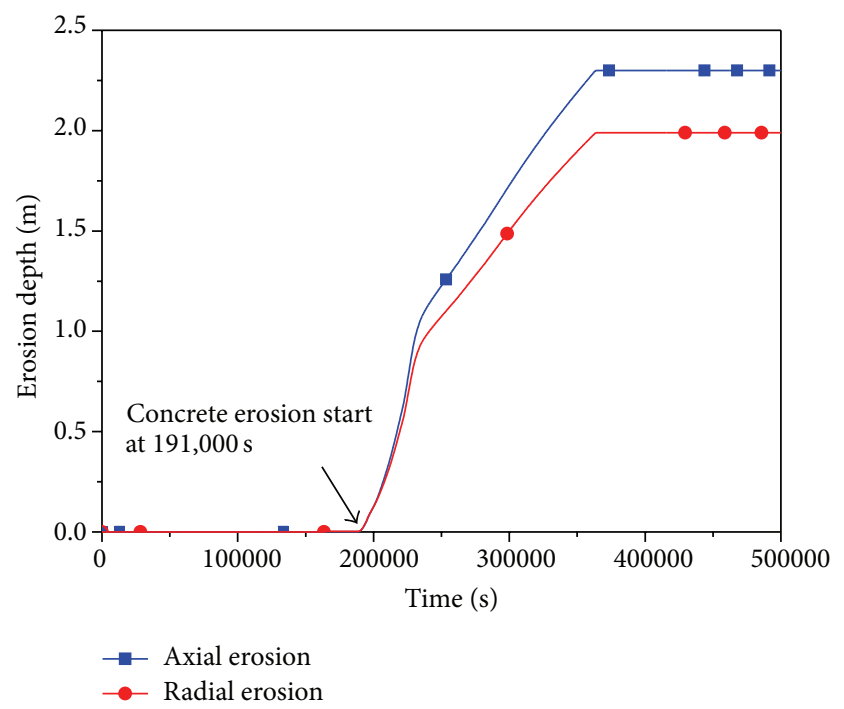

FIGURE 3: Axial/radial concrete erosion depth in the calandria vault.

of the basement floor. A great amount of steam generation results in a sudden pressure peak in the R/B. Figure 4 shows the pressure peak and the resulting $\mathrm{R} / \mathrm{B}$ failure at 102.4 hours $(368,484$ seconds), where the $\mathrm{R} / \mathrm{B}$ pressure of $427 \mathrm{kPa}(\mathrm{a})$ is applied as the $\mathrm{R} / \mathrm{B}$ failure pressure.

3.2. Uncertainty Analysis. In the severe accident analysis, there are uncertainties in the physical phenomena. There are also uncertainties in the ISAAC phenomenological models. Users had control over the uncertainties through the socalled "model parameters." They were either used as an input to a given physical model or to select between different physical models. This feature of the code architecture was 
TABLE 2: MCCI phenomena related uncertain parameters and distribution assumption.

\begin{tabular}{|c|c|c|c|c|}
\hline $\begin{array}{l}\text { MAAP uncertainty } \\
\text { parameters }\left(x_{i}\right)\end{array}$ & Parameter description & Most Likely Value & Range & Distribution \\
\hline$x_{1}=\mathrm{HTCMCR}$ & $\begin{array}{l}\text { Axial heat transfer coefficient (HTC) } \\
\text { from molten corium to lower crust }\end{array}$ & $3,500\left(\mathrm{~W} / \mathrm{m}^{2} \mathrm{C}\right)$ & {$[2,450,4,550]$} & Triangle \\
\hline$x_{2}=$ HTCMCS & $\begin{array}{l}\text { Radial HTC from molten corium to } \\
\text { side crust }\end{array}$ & $3,000\left(\mathrm{~W} / \mathrm{m}^{2} \mathrm{C}\right)$ & {$[2,100,3,900]$} & Triangle \\
\hline$x_{3}=\mathrm{FCHF}$ & $\begin{array}{l}\text { Flat plate CHF critical velocity } \\
\text { coefficient }\end{array}$ & 0.1 & {$[0.0036,0.3]$} & Log uniform \\
\hline$x_{4}=\mathrm{HTFB}$ & $\begin{array}{l}\text { Film boiling HTC from corium to an } \\
\text { overlying pool }\end{array}$ & $300\left(\mathrm{~W} / \mathrm{m}^{2} \mathrm{C}\right)$ & {$[100,400]$} & Triangle \\
\hline$x_{5}=\mathrm{LHDEC}$ & $\begin{array}{l}\text { Energy absorbed in endothermic } \\
\text { chemical reactions during basaltic } \\
\text { concrete decomposition }\end{array}$ & $275,000(\mathrm{~J} / \mathrm{kg})$ & {$[192,500,357,500]$} & Triangle \\
\hline$x_{6}=\mathrm{LHCN}$ & Latent heat of concrete melting & $560,000(\mathrm{~J} / \mathrm{kg})$ & {$[392,000,728,000]$} & Triangle \\
\hline$x_{7}=\mathrm{DCSRCN}$ & Rebar density & $600\left(\mathrm{~kg} / \mathrm{m}^{3}\right)$ & {$[420,780]$} & Triangle \\
\hline$x_{8}=\operatorname{ACMPLB}(1)$ & $\begin{array}{l}\text { Corium debris surface area in the } \\
\text { calandria vault }\end{array}$ & 62.54 & {$[50.03,62.54]$} & Uniform \\
\hline
\end{tabular}

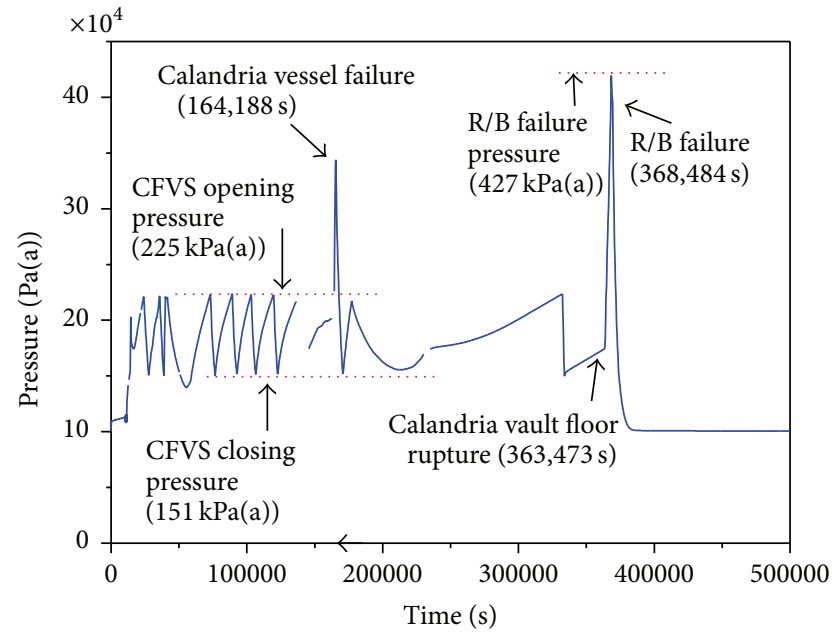

FIGURE 4: Pressure in the reactor building (R/B).

included specifically to facilitate sensitivity or uncertainty analysis. In this study, input variables related to model parameters that affect the calandria vault concrete erosion during severe accidents were identified, and their uncertainty was characterized using a user specified distribution. These parameters were selected based on ISAAC input parameter files [2].

For the present uncertainty analysis, eight inputs were selected and the corresponding uncertainty distributions were defined as shown in Table 2 . The most likely values of the eight parameters are given in the code documentation [2] while best-estimate value ranges are given for two parameters (FCHF, HTFB) in [3]. User assumptions are made given for the best-estimate value ranges of the other five parameters (HTCMCR, HTCMCS, LHDEC, LHCN, DCSRCN, and ACMPLB(1)) with a $30 \%$ increase or decrease from the most likely values. In order to propagate these uncertain inputs

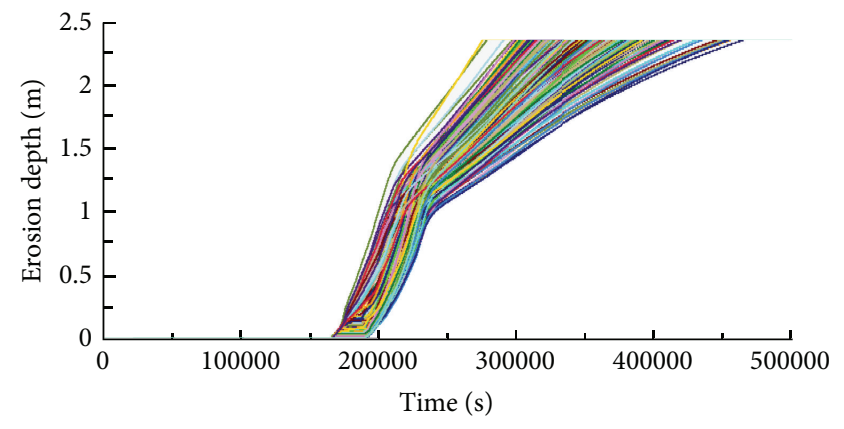

FIGURE 5: Samples of the distribution of axial concrete erosion depth in the calandria vault.

through the ISAAC code, they were sampled using the LHS technique. The LHS method selected $N$ values randomly from $N$ equally spaced intervals of the cumulative distribution, thereby ensuring a good sampling of the distribution tails with a minimum number of samples.

The results of the 200 ISAAC analyses constitute samples of the distribution of the MCCI related variables given the uncertainties expressed in Table 2. In this study, no dependency between parameters was considered in the sampling process, and thus all parameters were treated as independent.

The behavior of the axial concrete erosion in the calandria vault and the R/B pressure of all 200 ISAAC analyses are shown in Figures 5 and 6. Since this application was focused on determining an estimate of the concrete floor rupture time in the calandria vault which has a potential hazard of an $\mathrm{R} / \mathrm{B}$ failure, the calculation results for relevant variables were pointed out. The calculations were performed during 500,000 seconds.

As already mentioned, when the calandria vessel fails at 45.6 hours (164,188 seconds), the debris relocates into the calandria vault. Thereafter, the water depleted in the calandria vault and the corium again started to heat up and 


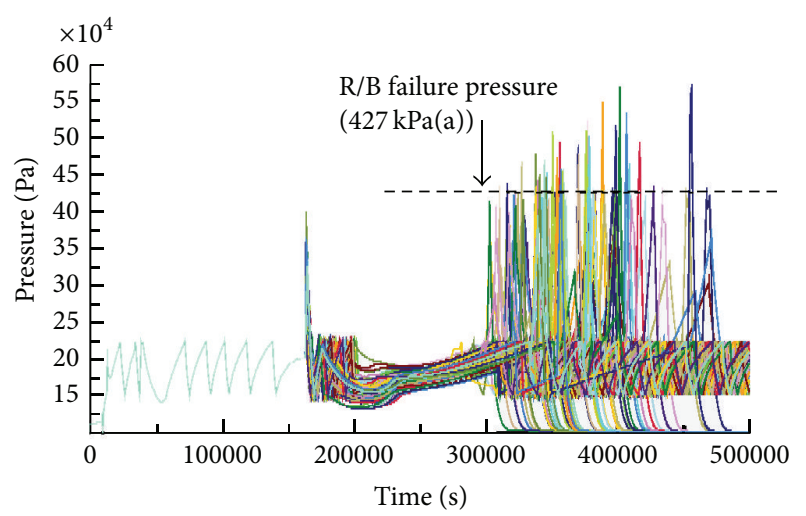

FIGURE 6: Samples of the distribution of pressure behaviors in the reactor building.

resulted in continuously increasing concrete ablation. It was assumed that the calandria vault floor would be ruptured if the erosion depth reached $2.3 \mathrm{~m}$ in all the 200 calculations. Figure 5 shows that the samples of the distribution of the calandria vault floor rupture time ranged between 76.2 and 128.9 hours $(274,474$ and 464,144 seconds). And the 5th and 95th percentiles of the rupture times were about 84 and 117 hours (303,000 and 420,000 seconds). Once the calandria vault floor ruptured, the corium discharged into the $\mathrm{R} / \mathrm{B}$ basement floor and a large amount of steam generated. A great amount of steam generation resulted in a sudden pressure peak in the reactor building. Figure 6 shows the samples of the distribution of the pressure peak. As uncertain parameters are related to phenomena occurring after core rupture and relocation in calandria vault, results only differ after 45.6 hours.

A potential hazard of the pressure peaks in Figure 6 is a failure of the reactor building. The calculation results show that the 5th and 95th percentiles of the maximum pressure were 234.8 and $516.6 \mathrm{kPa}(\mathrm{a})$. And the maximum pressure of 30 ISAAC analyses exceeded the $\mathrm{R} / \mathrm{B}$ failure pressure $(427 \mathrm{kPa}(\mathrm{a}))$. That means $15 \%$ of 200 analyses resulted in the $\mathrm{R} / \mathrm{B}$ failure during the time frame of $88.0-126.7$ hours (316,777-456,272 seconds).

In addition to characterizing the uncertainty distribution of the predicted concrete floor rupture time in the calandria vault, a type of linear regression analysis was also performed in order to identify which of the uncertain input parameters were most responsible for the uncertainty of the relevant output. As a result, two parameters to assess the importance in overall results were derived from the rank regression analysis for the output variable (calandria vault floor rupture time), the partial rank correlation coefficients (PRCC), and standardized rank regression coefficients (SRRC) [9]. A partial correlation coefficient (PCC) is a measure of the linear dependence of a pair of random variables from a collection of random variables in the case where the influence of the remaining variables is eliminated. A standardized regression coefficients (SRC) estimates resulting from an analysis carried out on variables that have been standardized so that their variances are 1 . This means the expected change in the
TABLE 3: Regression analysis results (number of samples: 200, sampling type: LHS).

\begin{tabular}{lcc}
\hline Input variables $\left(x_{i}\right)$ & \multicolumn{2}{c}{ Rupture time of calandria vault } \\
& SRRC & PRCC \\
\hline$x_{1}=$ HTCMCR & $-0.66(1)$ & $-0.96(1)$ \\
$x_{2}=$ HTCMCS & $0.51(2)$ & $0.93(2)$ \\
$x_{3}=$ FCHF & $0.08(7)$ & $0.38(7)$ \\
$x_{4}=$ HTFB & $0.02(8)$ & $0.07(8)$ \\
$x_{5}=$ LHDEC & $0.17(5)$ & $0.64(5)$ \\
$x_{6}=$ LHCN & $0.21(4)$ & $0.72(4)$ \\
$x_{7}=$ DCSRCN & $0.15(6)$ & $0.59(6)$ \\
$x_{8}=$ ACMPLB $(1)$ & $0.29(3)$ & $0.81(3)$ \\
$R^{2}(N=200)$ & $\mathbf{0 . 9 6}$ & $\mathbf{0 . 9 6}$ \\
\hline
\end{tabular}

Number in (): importance ranking.

dependent variable, per standard deviation increase in the predictor variable. PRCC and SRCC are PCC and SRC, respectively, based on ranks of the independent variables rather than their original values. The results of regression analyses are summarized in Table 3 .

As a result of the regression analysis, the coefficients of determination, $R^{2}$, were estimated to assess the goodness of fits. As shown in Table 3, the estimated coefficients of determination were enough to rank dominant inputs to the corresponding outputs according to their relative magnitudes, from a statistical point of view. Based on Table 3, the model inputs of "HTCMCR," "HTCMCS," and "ACMPLB(1)" were the key parameters to the concrete erosion in the calandria vault. The axial and radial erosion parameters (HTCMCR and HTCMCS, resp.) are competitive with each other. As long as the total decay heat generated in the molten corium is constant, the radial erosion depth is proportional to HTCMCR and inversely proportional to HTCMCS.

\section{Conclusion}

In this paper, a sampling-based uncertainty analysis was performed to statistically quantify uncertainties associated with molten corium-concrete interaction (MCCI), based on the key modeling parameters employed in the ISAAC code and LHS samples of those parameters. The accident sequence considered was a station blackout accident with the containment filtered vent system in operation, calculated for the Wolsong-1 plant. As a result, uncertainties related to the MCCI of the calandria vault were quantified as a function of time. Analyses results showed that the distribution of the calandria vault floor rupture time ranged between 76.2 and 128.9 hours $(274,474$ and 464,144 seconds). And the maximum $\mathrm{R} / \mathrm{B}$ pressure in $15 \%$ of analysis cases exceeded the $\mathrm{R} / \mathrm{B}$ failure pressure during the time frame of 88.0 126.7 hours (316,777-456,272 seconds). However, it should be emphasized that analyses results may be quite uncertain due to the limitation of the physical models and the adequacy or validity of the selected range of input variables. 
In addition to characterizing uncertainties related to MCCI, a type of linear regression analysis was performed in order to identify which of the uncertain input parameters were influencing the most the uncertainty of the relevant output. As a result, two influence measuring parameters (i.e., PRCC and SRRC) were derived for the calandria vault rupture time. The so derived ranks can be used to identify key areas where additional research may best be applied to further reduce the residual uncertainties of the predictions and thereby better apply limited research resources. The regression analysis results showed that the model inputs of "HTCMCR," "HTCMCS," and "ACMPLB(1)" were the key parameters to the concrete erosion in the calandria vault.

\section{Conflict of Interests}

The authors declare that there is no conflict of interests regarding the publication of this paper.

\section{Acknowledgments}

This work was supported by the National Research Foundation of Korea (NRF) grant funded by the Korea government (Ministry of Science, ICT, and Future Planning) (no. NRF2012 M2A8A4025966).

\section{References}

[1] KAERI, "Development of computer code for level 2 PSA of CANDU plant," Tech. Rep. KAERI/TR-1573/95, Korea Atomic Energy Research Institute, 1995.

[2] KAERI, WOLSONG 1 Nuclear Power Station Parameter File Version WS1-403R4D.PAR for ISAAC Program, Korea Atomic Energy Research Institute, 2013.

[3] EPRI, Modular Accident Analysis Program, 1994.

[4] S.-Y. Park and K.-I. Ahn, "Comparative analysis of station blackout accident progression in typical PWR, BWR, and PHWR," Nuclear Engineering and Technology, vol. 44, no. 3, pp. 311-322, 2012.

[5] R. O. Gauntt, "Uncertainty analyses using the MELCOR severe accident analysis code," in Proceedings of the OECD Workshop, SNL, Aix-en-Provence, France, November 2005.

[6] USNRC, MELCOR Computer Code Manuals, NUREG/CR-6119, Sandia National Laboratories, 1990.

[7] H. G. Lim and S. H. Han, "Development of T/H uncertainty analysis S/W MOSAIQUE," in Proceedings of the 10th KoreaJapan Joint Workshop on PSA (KJPSA '09), May 2009.

[8] S. Y. Park, H. Y. Jin, and M. Y. Song, "An investigation of an in-vessel corium retention strategy for the wolsong pressurized heavy water reactor," Nuclear Technology, vol. 158, pp. 109-115, 2007.

[9] K.-I. Ahn, S.-H. Park, H.-D. Kim, and H. S. Park, “The plantspecific uncertainty analysis for an ex-vessel steam explosioninduced pressure load using a TEXAS-SAUNA coupled system," Nuclear Engineering and Design, vol. 249, pp. 400-412, 2012. 


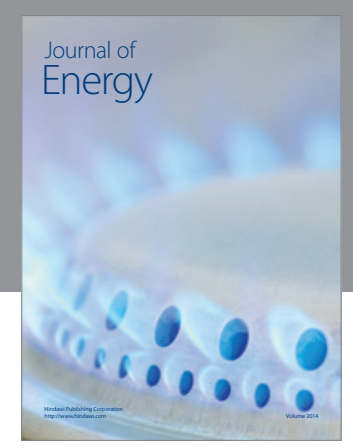

Journal of

Industrial Engineering
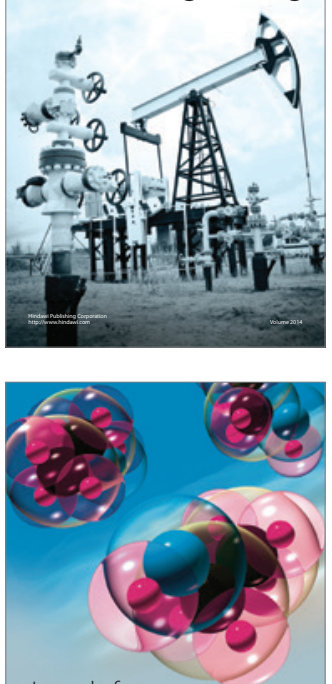

Fuels
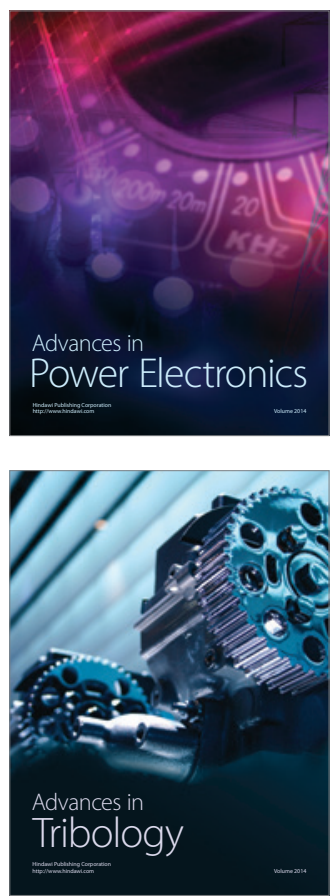

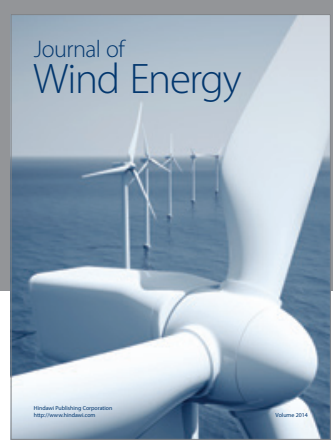

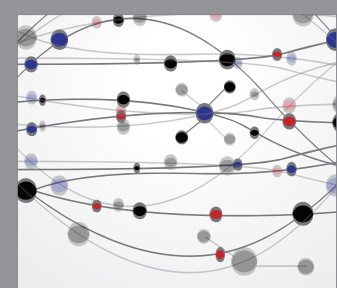

The Scientific World Journal

Submit your manuscripts at http://www.hindawi.com

Journal of

Structures
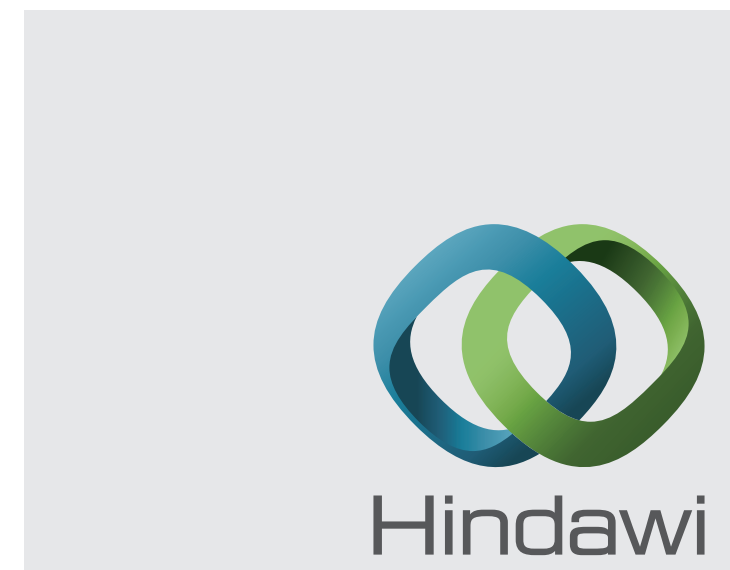

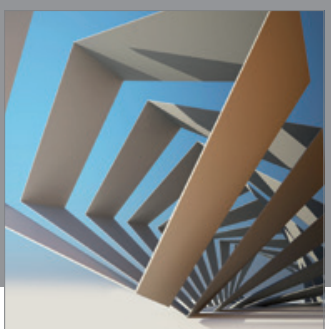

Rotating

Machinery
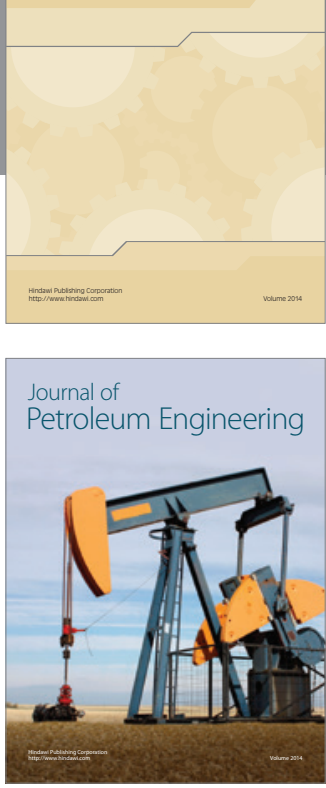

Journal of

Solar Energy
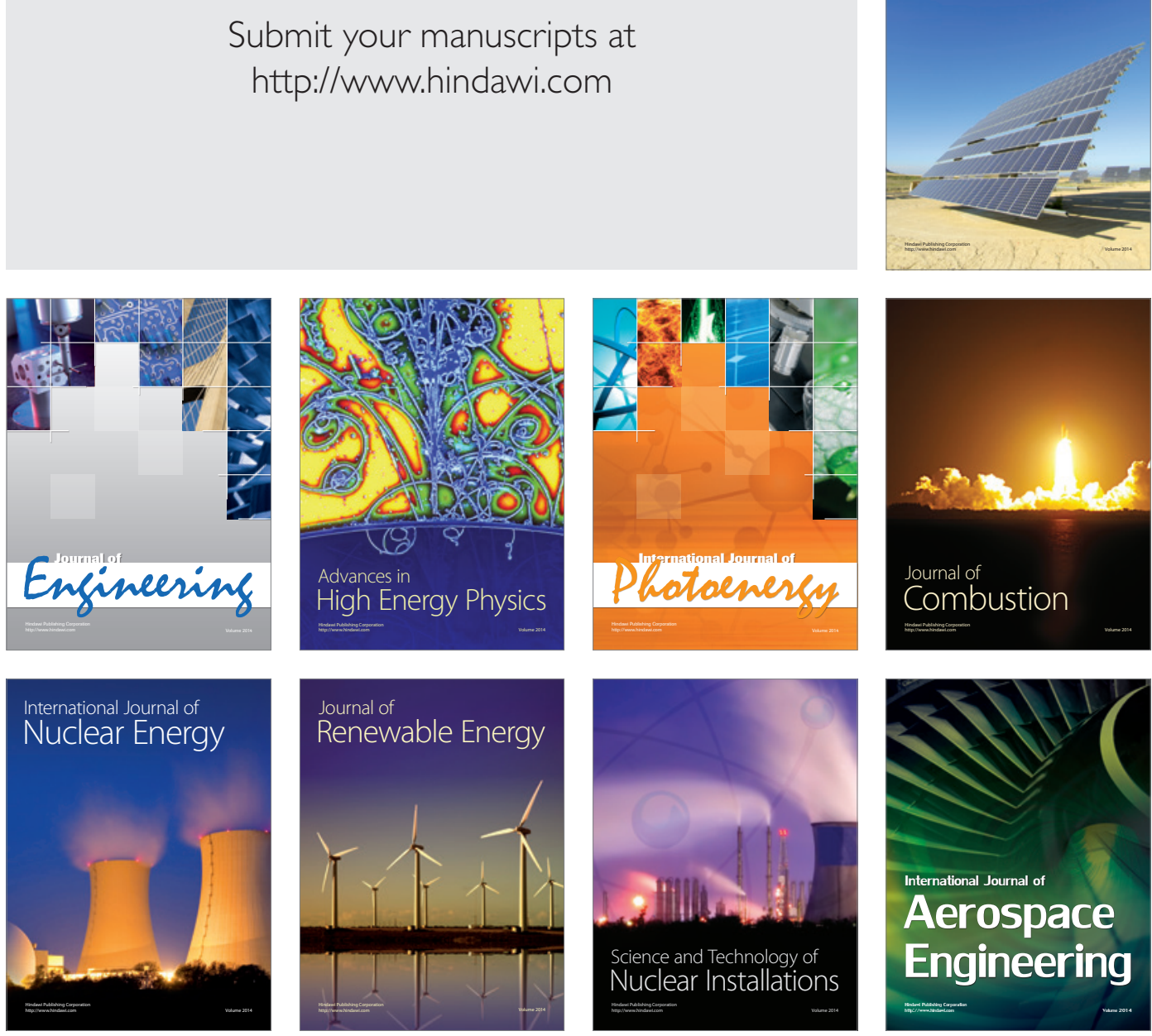